\section{Wer ist ... \\ Carola Berking?}

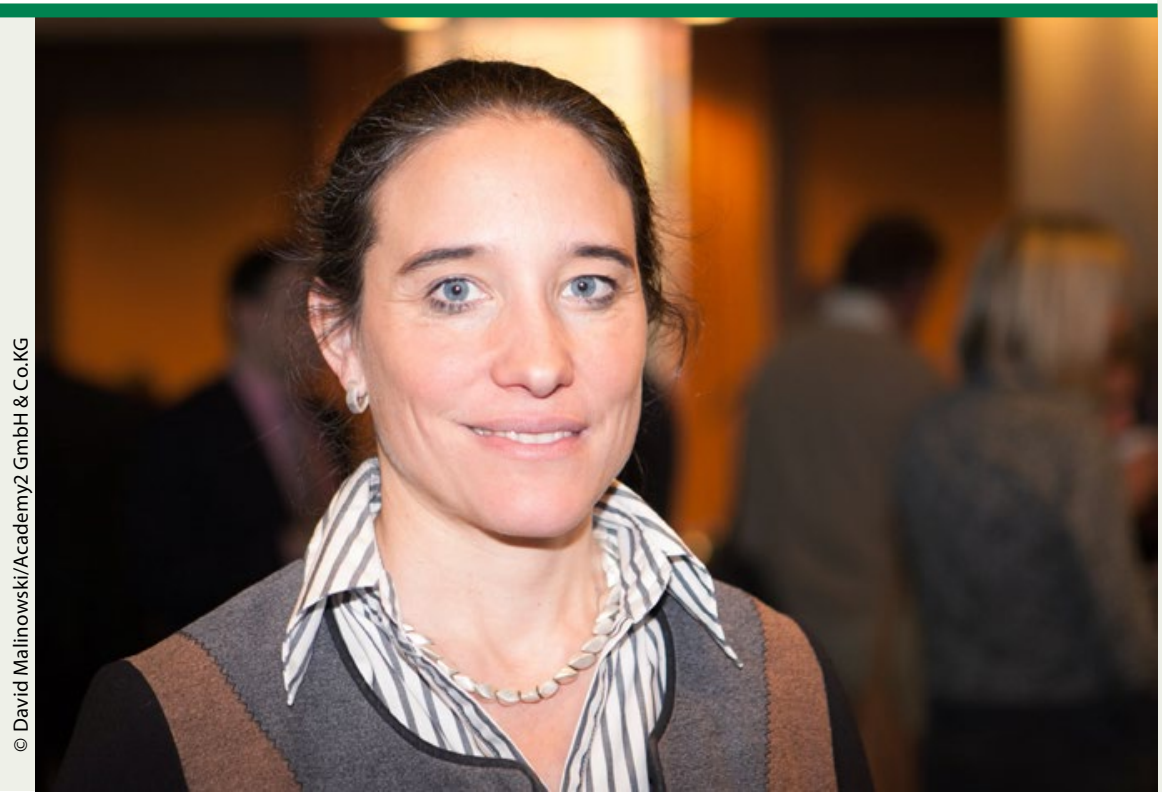

Wie beginnen

Sie Ihren Tag?

Berking: Mit einer großen Tasse heißen Earl-Grey-Tee, Dehnungsgymnastik und dem Morgenmagazin.

\section{Was treibt}

Sie an?

Berking: Wissenschaftliche Neugier und ein großes Maß an Optimismus.

\section{Als Kind}

wollten Sie ...?

Berking: ...nicht mit Puppen spielen, mal Schauspielerin, mal Lehrerin werden, unbedingt aber in einer bekannten Universitätsstadt studieren.
Behandeln, Forschen und den akademischen Nachwuchs fördern - Professorin Carola Berking, Fachärztin für Haut- und Geschlechtskrankheiten, ist in allen drei Bereichen sehr aktiv: Nach Ausbildungsstationen in Saarbrücken, München und New York betreut sie seit 2008 als Oberärztin Patienten an der Klinik und Poliklinik für Dermatologie und Allergologie der Ludwig-Maximilians-Universität (LMU) München. In der Forschung hat Berking u. a. einschlägige Arbeiten zur Relevanz von neuronalen Transkriptionsund Wachstumsfaktoren für die Entstehung und Progression des malignen Melanoms publiziert. Als leitende Prüfärztin hat sie an mehr als 40 klinischen Studien mitgewirkt. Und in der Nachwuchsförderung engagiert sich Berking als Tutorin und Mentorin, etwa für Stipendiaten der Initiative LMUexcellent und des Max-Weber-Programms in Bayern. Auch sie selbst hat im Laufe ihrer Karriere etliche Stipendien und Preise erhalten, darunter ein Auslandsstipendium der Deutschen Forschungsgemeinschaft (Wistar-Institut Philadelphia, PA/USA), den Ingrid-zu-Solms-Wissenschaftspreis und den Therese von Bayern-Preis.

Was war Ihre wichtigste

Entscheidung?

Berking: Meine wichtigsten Entscheidungen waren, Medizin zu studieren und mit meinem Mann Kinder zu bekommen.

Beispiel in der bildenden Kunst, Instrumentalmusik oder Physik. Und der Terminkalender von Politikern.

\section{Worauf sind Sie}

besonders stolz?

Berking: Als Mentorin gefragt und ins Vertrauen gezogen zu werden.

\section{Was möchten Sie noch} erreichen?

Berking: Meinen Patienten mit metastasiertem Hautkrebs wahrhaftig Heilung und nicht nur Aufschub und Linderung versprechen zu dürfen. Mit meinem Mann möglichst alle schönen Radwanderwege durch Europa zu schaffen.
Wie halten Sie Balance in Ihrem Leben?

Berking: Ich verbringe gerne Zeit mit meinen Kindern - und mit Spaziergängen, Musik hören, Radfahren und Bergwandern.

Wie beenden Sie

Ihren Tag?

Berking: Vor dem Schlafengehen werfe ich immer noch einen Blick auf meine schlafenden Kinder. 